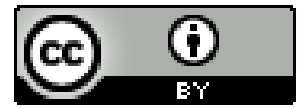

\title{
UMA HISTÓRIA AFIRMATIVA. AS COTAS RACIAIS 20 ANOS
}

\section{DEPOIS}

\author{
Renato Ferreira ${ }^{1}$ \\ Universidade Federal Fluminense (UFF), Niterói, RJ Brasil.
}

\begin{abstract}
Resumo: O presente artigo visa retratar e refletir sobre o processo de construção e desdobramentos sociais das políticas de cotas raciais nas universidades estaduais no Rio de Janeiro. Na primeira parte do artigo daremos ênfase às questões sócio históricas abordando as tensões causadas pela implementação das ações afirmativas. Já no segundo momento, o texto refere-se aos impactos e desdobramentos das cotas que se estabilizaram como políticas de Estado, após o Supremo Tribunal Federal ter declarado, por unanimidade, a sua constitucionalidade. Por fim, traremos um panorama sobre os dados inclusivos dos programas de cotas raciais, bem como os desafios dessas medidas que se tornaram as maiores políticas de democratização do acesso às instituições de ensino superior no Brasil.
\end{abstract}

Palavras-chave: Democratização do acesso à educação superior; Ações afirmativas nas universidades; sistema de cotas raciais.

\section{AN AFFIRMATIVE STORY. THE RACIAL QUOTAS 20 YEARS LATER}

Abstract: This article aims to portray and reflect on the process of construction and social developments of racial quota policies in state universities in Rio de Janeiro. In the first part of the article, we will emphasize socio-historical issues addressing the tensions caused by the implementation of affirmative action. In the second moment, the text refers to the impacts and consequences of the quotas that stabilized as State policies, after the Federal Supreme Court unanimously declared their constitutionality. Finally, we will bring an overview of the inclusive data brought by racial quota programs, as well as the challenges of these measures that have become the biggest policies for democratizing access to higher education institutions in Brazil.

Keywords: Democratization of access to higher education; Affirmative Actions in Universities; racial quota system.

\section{UNA HISTORIA AFIRMATIVA. LAS CUOTAS RACIALES 20 AÑOS DESPUÉS}

\footnotetext{
${ }^{1}$ Formado em Direito, Mestre em Políticas Públicas e Doutorando em Sociologia e Direito (PPGSD) UFF, RJ Brasil. Foi membro da Comissão mista da UERJ, ALERJ e Governo do Estado responsável por implementar a primeira política de cotas raciais nas universidades estaduais do Rio de Janeiro. E-mail: natoferreiraadv@gmail.com ; ORCID: https://orcid.org/0000-0002-2116-5862
}

Revista da ABPN • v. 13, n. $38 \cdot 2021 \cdot$ p. $422-442$ 
Resumen: Este artículo tiene como objetivo retratar y reflexionar sobre el proceso de construcción y desarrollo social de las políticas de cuotas raciales en las universidades estatales de Río de Janeiro. En la primera parte del artículo, enfatizaremos temas sociohistóricos que abordan las tensiones causadas por la implementación de la acción afirmativa. En el segundo momento, el texto se refiere a los impactos y consecuencias de las cuotas que se estabilizaron como políticas de Estado, luego de que el Supremo Tribunal Federal declarara por unanimidad su constitucionalidad. Finalmente, traeremos un resumen de los datos inclusivos que aportan los programas de cuotas raciales, así como los desafíos de estas medidas que se han convertido en las mayores políticas para democratizar el acceso a las instituciones de educación superior en Brasil.

Palabras Clave: Democratización del acceso a la educación superior; Acciones afirmativas en universidades; sistema de cuotas raciales.

\section{UNE HISTOIRE POSITIVE. LES QUOTAS RACIAUX 20 ANS PLUS TARD}

Résumé: Cet article vise à décrire et à réfléchir sur le processus de construction et les développements sociaux des politiques de quotas raciaux dans les universités d'État de Rio de Janeiro. Dans la première partie de l'article, nous mettrons l'accent sur les questions socio-historiques abordant les tensions causées par la mise en œuvre de l'action positive. Dans un second temps, le texte évoque les impacts et les conséquences des quotas qui se sont stabilisés en tant que politiques de l'État, après que la Cour suprême fédérale a déclaré à l'unanimité leur constitutionnalité. Enfin, nous apporterons un aperçu des données inclusives apportées par les programmes de quotas raciaux, ainsi que les défis de ces mesures qui sont devenues les plus grandes politiques de démocratisation de l'accès aux établissements d'enseignement supérieur au Brésil.

Mots-clés: Démocratisation de l'accès à l'enseignement supérieur ; Actions positives dans les universités ; système de quotas raciaux.

\section{INTRODUÇÃO}

No início dos anos 2000 vivíamos o limiar de transformações sociais importantes por conta da entrada em vigor das primeiras leis que instituíram políticas públicas de ações afirmativas, sob a modalidade de sistema de cotas, nas universidades estaduais do Rio de Janeiro ${ }^{2}$. Há nesta história muitos significados, mas destacamos ao menos dois. Com as cotas, pela primeira vez estudantes negros ingressariam de forma significativa no ensino superior, mormente em faculdades mais elitistas como Direito, Medicina,

\footnotetext{
${ }^{2}$ Outros Órgãos federais já tinham adotado sistemas similares até que este tipo de medida fosse adotado por uma universidade. As universidades em questão são a Universidade do Estado do Rio de Janeiro (UERJ) e Universidade do Norte Fluminense Darcy Ribeiro (UENF).
} 
Engenharia, etc., onde a presença desse grupo era residual ${ }^{3}$. Ressalte-se ainda que essas políticas, além de tornarem mais democrático o acesso às universidades, também poriam fim a longa hegemonia da "democracia racial" nas políticas da educação superior brasileira. $^{4}$

Antes de entrar propriamente na análise das políticas de cotas é importante ressaltar que as mesmas se inserem num contexto maior de evolução das lutas dos Movimentos Sociais Negros contra o racismo. Neste sentido, importa dizer que a discriminação racial se desenvolveu como espécie de pilar ideológico na formação e estruturação da sociedade brasileira. A discriminação mediou por centenas de anos e por diversas gerações as relações sociais estabelecidas em nossa sociedade, hierarquizando-a injustamente com base na subjugação da população negra. Por outro lado, o fim da escravidão não foi seguido de políticas públicas antirracistas que teriam contribuído para romper com os séculos de atraso que nos prenderam e nos prendem até hoje aos grilhões de uma pré-modernidade legada pela injustiça de nossos colonizadores.

A secular inércia pública contra o racismo, a baixa densidade de nosso estado de bem-estar, somados a uma boa dose de democracia racial, consolidaram uma abolição inconclusa e, por esta narrativa histórica, cristalizaram o apartheid que nos coube: disfarçado, sinuoso, mas terrivelmente eficaz, não só para permitir que muitas desigualdades continuassem baseadas nas diferenças, mas também para sustentar uma enorme invisibilidade para o problema. Desta forma, estabeleceu-se uma profunda

\footnotetext{
${ }^{3}$ O termo "negros" aqui está em consonância com a lei 12288/10 (Estatuto da Igualdade racial). "Art. 1 Esta Lei institui o Estatuto da Igualdade Racial, destinado a garantir à população negra a efetivação da igualdade de oportunidades, a defesa dos direitos étnicos individuais, coletivos e difusos e o combate à discriminação e às demais formas de intolerância étnica.

Parágrafo único. Para efeito deste Estatuto, considera-se:

I- (...)

IV - população negra: o conjunto de pessoas que se autodeclaram pretas e pardas, conforme o quesito cor ou raça usado pela Fundação Instituto Brasileiro de Geografia e Estatística (IBGE), ou que adotam autodefinição análoga."

${ }^{4}$ Sobre a democracia racial, assim escreveu Florestan Fernandes: "Na ânsia de prevenir tensões raciais hipotéticas e de assegurar uma via eficaz para a integração gradativa da população de cor, fecharam-se todas as portas que poderiam colocar o negro e o mulato na área dos benefícios diretos do processo de democratização dos direitos e garantias sociais. Pois é patente a lógica desse padrão histórico de justiça social. Em nome de uma igualdade perfeita no futuro, acorrentava-se o homem de cor aos grilhões invisíveis do seu passado, a uma condição sub-humana de existência e a uma disfarçada servidão eterna. Como não poderia deixar de suceder, essa orientação gerou um fruto espúrio. A ideia de que o padrão brasileiro de ralações entre brancos e negros se conformava aos fundamentos ético-jurídicos do regime republicano vigente. Engendrou-se assim um dos grandes mitos de nossos tempos: o mito da democracia racial brasileira.".
} 
letargia nos governantes, impedindo a construção de políticas que nos teriam feito romper com desigualdades incompatíveis com o estado democrático de direito.

Diante deste histórico, a construção de políticas públicas antirracistas no Brasil é relativamente recente ${ }^{5}$. Somente a partir dos anos 1980 é que os movimentos sociais negros conseguem paulatinamente sensibilizar o Estado para esta agenda. Um marco neste período é a superação da vã tentativa de enfrentar a discriminação, categorizando o racismo como contravenção penal. ${ }^{6}$ Neste sentido, o processo de elaboração da Constituição de 1988 contribui significativamente para a construção das normas de combate à discriminação de forma ampla. Com base na valorização dos povos que constituíram o Brasil, a Carta Magna marca um significativo avanço para a efetividade dos direitos fundamentais dos grupos tradicionalmente excluídos. Por diversos de seus dispositivos, a Lei Maior rompe com o mito da democracia racial, tornando o racismo crime (art. $5^{\circ}$, XLII) e assegurando o direito à diferença, ao reconhecer e valorizar as especificidades étnico-raciais, sociais, religiosas e culturais dos povos que ajudaram a formar a sociedade brasileira (art. 215) ${ }^{7}$.

Em 1995 o Movimento Negro realiza a Marcha Zumbi Contra o Racismo, pela Cidadania e a Vida. Este evento serviu para exigir que o Governo Federal tomasse uma postura em relação à discriminação racial produzindo algumas ações afirmativas. Ressalte-se que, mesmo com toda luta do Movimento Negro, este período é marcado pelo neoliberalismo nas políticas e nesta época o enfrentamento do poder público ao racismo era tímido em discurso, simbólico no reconhecimento e pouco eficaz na política, denotando um profundo mal-estar diante da questão que só avança por meio de um processo político exógeno, devido à pressão internacional sofrida pelo Brasil durante a Conferência de Durban, na África do Sul em $2001^{8}$.

\footnotetext{
${ }^{5}$ Uma boa reflexão sobre o avanço da luta antirracista no contexto da promoção da igualdade racial é fornecido por Amauri Mendes no artigo "Toma que o filho é seu". Disponível em http://www.abpn.org.br/Revista/. Consultado em 14.01.2013.
}

${ }^{6}$ A exemplo tivemos a Lei Afonso Arinos - $\mathrm{n}^{\circ}$ 1.390, de 3 de julho de 1951 que incluia entre as contravenções penais a prática de atos resultantes de preconceitos de raça ou de cor.

${ }^{7}$ No mesmo sentido, vide O Manifesto em Defesa das Cotas. Disponível em http://www1.folha.uol.com.br/fsp/cotidian/ff1405200808.htm. consultado em 12.01.2013.

\footnotetext{
${ }^{8}$ As políticas afirmativas começam a ser construídas no período neoliberal. Neste sentido, como forma de organização e atuação política do Estado, constitui-se como um vetor de precarização e não desenvolvimento do Estado de bem-estar social. Por meio de políticas de abertura econômica, privatização, flexibilização, desregulamentação do mercado, redução dos investimentos públicos etc., ele acabou por promover um profundo desajuste social. As políticas neoliberais tentam redefinir o papel da sociedade civil,
} 
Neste período o Governo Federal teve que reconhecer a importância do racismo, como um dos fatores estruturais e determinantes para a perpetuação das desigualdades sociais, e começar de forma tímida a criar algumas políticas de ação afirmativa ${ }^{9}$.

É neste contexto de avanços democráticos antirracistas que devemos assentar a construção das primeiras políticas de cotas raciais na educação superior. Elas por um lado, marcam o fim de uma era de ativismos pautados mais na denúncia e críticas à democracia racial, e por outro lado, traduzem-se no limiar de uma nova era antirracista consubstanciada na construção de políticas públicas e ações privadas para a promoção da igualdade racial.

Desta forma, o impacto político trazido pela Conferência de Durban, além de impulsionar algumas ações do Governo Federal, influenciou a Assembleia Legislativa do Rio de Janeiro (Alerj) que cria o sistema de cotas raciais nas universidades do Estado ${ }^{10}$.

\section{CONSTRUÇÃO E REAÇÃO ÀS POLÍTICAS DE COTAS ${ }^{11}$}

concebendo os movimentos sociais como meros espectadores do processo de opressão e/ou como substitutos estatais. Busca-se vestir nos movimentos a carapuça de terceiro setor, por intermédio do apoio às ONGs. Assim, tenta-se fazer com que essas instituições assumam de forma precária o papel do Estado na construção de políticas públicas de promoção da igualdade racial. Tome-se como exemplo o Programa Diversidade na Universidade. Como única política desse período para promover o ingresso de negros e indígenas no ensino superior, o referido Programa ajudava financeiramente os chamados cursinhos comunitários (de ONGs) a preparar alunos carentes para o vestibular. Esta ação do Ministério da Educação era apresentada como a grande estratégia para o acesso de grupos excluídos às universidades públicas e por muitas vezes tal política era usada por membros do governo para negar a promoção das políticas de cotas raciais.

\footnotetext{
${ }^{9}$ Podemos destacar a Portaria n. 202 de 4 de setembro de 2001 do Ministério de Estado do Desenvolvimento Agrário, a rigor, foi a primeira política de cotas para negros no Brasil. Ela instituiu cotas de $20 \%$ para negros nos cargos de direção do Ministério. A portaria determinou ainda que o referido percentual fosse elevado até chegar a 30\% no ano de 2003. Outros Órgãos governamentais adotaram sistemas similares. A portaria 1156/01 do Ministério da Justiça criou 20\% de cotas para afrodescendentes, o Decreto 3921/01 regulamentou a identificação para o reconhecimento, delimitação, demarcação e titulação das terras remanescentes de Quilombos, o Protocolo de Cooperação sobre Ação Afirmativa no Instituto Rio Branco (2002), que passou a fornecer bolsas prêmio de vocação na diplomacia para afrodescendentes. Destaque-se também, a Portaria n. 484/02 na qual o Ministério da Cultura estabeleceu cota de 20\% para afrodescendentes nos cargos de direção e assessoramento superior DAS e a Lei 10558/02 que instituiu o Programa Diversidade na Universidade, com objetivo de promover o acesso de pessoas pertencentes a grupos socialmente desfavorecidas, principalmente, os afrodescendentes e indígenas ao ensino superior. Ressalte-se ainda o decreto 4228 em 13 de maio de 2002 que criou um programa de ações afirmativas na administração pública federal, mas que padece até hoje de efetividade.
}

${ }^{10}$ Vale ressaltar que a exposição de motivos do projeto que resultou na lei 3708/01 (que destinou 40\% de vagas para negros), se reporta expressamente à Conferencia de Durban, chamando atenção dos deputados para importância de aproveitar aquele evento internacional para aprovar o referido projeto de lei.

11 Para Gomes, as políticas de ações afirmativas configuram: (...) um conjunto de políticas públicas e privadas de caráter compulsório, facultativo ou voluntário, concebidas com vistas ao combate à discriminação racial, de gênero e de origem nacional, bem como para corrigir os efeitos presentes da 
O primeiro sistema de cotas era formado por uma combinação de três legislações complexas construídas em processos e tempos distintos. ${ }^{12}$ A redação dos dispositivos normativos causava confusão na interpretação, os percentuais de vagas eram sobrepostos e muito elevados, empregando equivocadamente expressões como "negros e pardos". Estes fatos potencializaram em muito o movimento contrário às ações afirmativas nas universidades ${ }^{13}$.

Em especial na UERJ onde havia muita resistência sobre a necessidade desse tipo de política para promover o acesso de grupos excluídos à graduação. Os opositores, de um modo geral, sustentavam que a lei feria a autonomia universitária, e assim reivindicavam que tais políticas deveriam ser adotadas por decisão do conselho da academia. Também argumentavam que o sistema de cotas subvertia o mérito no ingresso e faria cair "o nível" das universidades, afirmavam também que a inclusão deveria ser dos pobres e não dos negros e apostaram que as cotas gerariam tensões raciais entre os discentes, causando ainda estigma nos alunos advindos desse sistema ${ }^{14}$.

Para tentar retratar melhor estes fatos, passemos a descrever a reação ao sistema de cotas raciais em alguns campos sociais de disputa ${ }^{15}$.

discriminação praticada no passado, tendo por objetivo a concretização do ideal de efetiva igualdade de acesso a bens fundamentais como a educação e o emprego. (2001, p. 40).

${ }^{12}$ A lei 3534/00 estabelecia cotas de 50\% para estudantes oriundos da escola pública, a lei 3708/01 que destinou $40 \%$ das vagas para estudantes negros e pardos (sic) e a lei 4.061/03 que reservava 10\% das vagas para pessoas com deficiência. Essas leis faziam parte de um sistema de avaliação do ensino médio estabelecendo provas que seriam aplicadas aos alunos no fim de cada ano do referido ensino. Primeiro se deveria preencher a cota de $50 \%$ da escola pública depois observar qual o percentual de negros havia dentre esses alunos. O problema ocorreu porque em alguns cursos, dentre os alunos da escola pública não havia negros. Isso determinava que a universidade deveria buscar preencher a cota de $40 \%$ com alunos oriundos das escolas privadas. Esse fato em alguns casos geral uma sobre posição das cotas que em alguns cursos, como Comunicação Social, chegou a um percentual maior do que 60\%.

${ }^{13}$ No ano de 2000, a Assembleia Legislativa do Estado do Rio de Janeiro (Alerj) aprovou a Lei $\mathrm{n}^{\circ}$ 3.524/2000, que introduziu modificações nos critérios de acesso às universidades estaduais fluminenses e reservou 50\% das vagas para estudantes egressos de escolas públicas.4 E, em 2001, a Alerj aprovou a Lei $\mathrm{n}^{\mathrm{o}} 3.708 / 2001$, que destinava $40 \%$ de vagas para candidatos auto-declarados negros e pardos.5 Em 2003, essas leis foram modificadas e substituídas pela Lei $n^{\circ}$ 4.151/2003. A legislação compreende ainda as leis $\mathrm{n}^{\mathrm{o}} 5.074 / 2007 \mathrm{e} \mathrm{n}^{\circ} 5.346 / 2008$

${ }^{14}$ A partir de 2013, o vestibular estadual, além da UERJ e UENF, também conta com o Centro Universitário Estadual da Zona Oeste (UEZO); Academia de Bombeiro Militar D. Pedro II (ABM D. Pedro II) do Corpo de Bombeiros Militar do Estado do Rio de Janeiro (CBMERJ).

15 A expressão campo aqui está no mesmo sentido que é desenvolvido por Pierre Bourdieu, para quem o campo social se mostrará como espaço estruturado de posições sociais. Essas posições sociais não são definidas pelos indivíduos que as ocupam, mas os próprios indivíduos precisam ocupá-las para agirem socialmente, para desempenharem suas estratégias, para serem alguém no mundo social. O campo tende a substituir a noção de sociedade, na medida em que contém determinadas características irredutíveis que 
No Congresso Nacional havia forte tensão com embates pela aprovação de projetos leis que visavam criar políticas públicas de promoção da igualdade racial em setores como saúde, educação e marcado de trabalho. A resistência mais aguda se dava contra a aprovação do sistema de cotas nas universidades federais e o Estatuto da Igualdade Racial. A temática dividia os parlamentares, foram feitas diversas audiências públicas e reuniões que aos poucos surtiram efeito e fizeram o Congresso aprovar as referidas leis ${ }^{16}$.

No campo acadêmico, as universidades alegavam que as leis de cotas violavam sua autonomia universitária. As instituições não participaram ativamente do processo de elaboração das referidas normas na Assembleia Legislativa do Estado. O acordo político que resultou nas referidas leis teve maior participação do Governo, deputados e Movimento Social. Esse fato ressentia a comunidade acadêmica que via a legislação como uma afronta ao seu poder de decidir, por meio de seu conselho superior, se deveria ou não, adotar tal política.

No campo do Direito houve grande judicialização, uma profusão de demandas. Contra o sistema de cotas foram propostas, logo no início, cerca de quatrocentas ações, uma Ação Direta de Inconstitucionalidade no Supremo Tribunal Federal (STF), duas Representações de Inconstitucionalidade (no Órgão Especial do Tribunal de Justiça), uma Ação Civil Pública, além de um Inquérito Civil, no Ministério Público, proposto por entidades do Movimento Negro (alegando que a UERJ não estaria coibindo as fraudes à auto-identificação) ${ }^{17}$. Estava em jogo a luta pela legitimidade jurídica das políticas afirmativas. $^{18}$

impedem uma total integração a uma totalidade (que poderia ser representada pela noção de sociedade). Desta forma, a coisa que se chama de sociedade é, na verdade, "constituída por um conjunto de microcosmos sociais dotados de autonomia relativa, com lógicas e possibilidades próprias, específicas, com interesses e disputas irredutíveis ao funcionamento de outros campos. Conforme Siqueira Vinicius "O campo social de - Pierre Bourdieu". Publicado em https://colunastortas.com.br/bourdieu-campo/. Consultado em outubro, 2021.

${ }^{16}$ Uma pesquisa feita pelo Programa Políticas da Cor do Laboratório de Póliticas Públicas da UERJ em 2006, revelou que havia quarenta e nove projetos de lei com o objetivo de criar ações afirmativas em diversas áreas.

${ }^{17}$ Num primeiro momento houve deferimento de mais de 161 liminares contrárias às cotas, os juízes determinavam a imediata matrícula dos estudantes, tidos como preteridos, declarando a inconstitucionalidade das políticas de inclusão no caso concreto.

${ }^{18}$ Uma boa amostra dos argumentos contrários e favoráveis ao sistema de cotas pode ser visto em "Os 10 mitos contra as cotas". Disponível em https://www.geledes.org.br/10-mitos-sobre-as-cotas/ . Consultado em 10.10.2021. 
Objetiva-se saber se elas se coadunavam, por exemplo, com o princípio da igualdade, da proporcionalidade, do mérito, se davam azo à fraude e se iriam fomentar divisões, ódios raciais, etc.

No campo midiático levantaram-se contra as ações afirmativas os mais poderosos meios de comunicação. Dezenas de artigos, pondo em xeque a legitimidade das cotas, foram publicados cotidianamente. Reportagens, entrevistas, artigos saltaram dos jornais e revistas televisivas, eletrônicas ou impressas querendo fazer crer, ainda que sem base em qualquer dado científico - mesmo quando a argumentação partia de acadêmicos respeitáveis - que as políticas afirmativas para negros eram, em si, um erro. ${ }^{19}$ Os que seguiam essa tese, afirmavam que as cotas estavam criando "divisões perigosas" que cindiriam o país racialmente. ${ }^{20}$

Neste contexto, um grupo de intelectuais e ativistas se autoproclamaram "113 cidadãos anti-raciais" e entregaram para os chefes do Poder Legislativo e do Poder Judiciário dois manifestos contra as ações afirmativas causando grande repercussão pública.

Por conta de toda essa polêmica, o primeiro sistema de cotas raciais foi revogado dando lugar à uma política pública mais razoável. ${ }^{21}$ No processo de construção deste novo

\footnotetext{
${ }^{18}$ No início de debate sobre implementação das cotas na UERJ, Nilcea era contrária às políticas. Muito pressionada por setores conservadores da universidade, ela chegou a defender a inconstitucionalidade do sistema na mídia e em artigos de jornais da época. Sua postura começa a mudar a partir do momento em que ela, uma mulher progressista e sensível às causas sociais, começa a dialogar com os movimentos pró cotas. Ela participou de algumas reuniões da Educafro com muitos alunos da Baixada Fluminense e das comunidades. Destaque para uma reunião em Nilópolis na qual ela testemunhou o depoimento dos vestibulandos relatando seus sonhos de ingressar para a UERJ. Lembramos ainda o "episódio das correntes", no qual alunos do Educafro se acorrentaram nos portões da UERJ com o objetivo de fazer com que a reitoria implementasse a primeira lei de cotas. Esse episódio foi registrado pela imprensa e as imagens fizeram parte de um documentário da BBC de Londres sobre a exclusão dos negros nas universidades brasileiras.

${ }^{19}$ Os Manifestos foram entregues nos anos de 2007 e 2008. Ambos contaram com a assinatura de intelectuais, artistas e várias personalidades. Ressalte-se que, houve um movimento em defesa das cotas. Em resposta também entregou dois Manifestos às autoridades referidas.

${ }^{20} \mathrm{Um}$ argumento contrário frequentemente utilizado, afirmava que as ações afirmativas aumentariam os conflitos raciais. Pesquisa do Grupo de Estudos Multidisciplinares da Ação Afirmativa da Uerj, no entanto, conclui que, os programas criados "não produziram nenhuma tendência de exacerbação do conflito racial ou mesmo de racialização do espaço universitário"
}

${ }^{21}$ É importante destacar também neste processo de construção das cotas a participação do Coronel da Polícia Militar Jorge da Silva (que foi Secretário de Estado) e do Jornalista Carlos Alberto Medeiros, que estavam assessorando o Governo do Estado nesta construção.

${ }^{21}$ Defender as cotas raciais como uma das formas de combater as desigualdades estruturais não era algo fácil, num tempo em que reitores não recebiam os movimentos sociais para dialogar, muito menos para construir política universitária. A participação da reitoria da universidade como gestora ajudou a construir uma das políticas públicas mais importantes pela democratização do país nos últimos anos. Como podemos 
sistema (mais estável que reduziu as ações judiciais, a resistência interna das instituições, além de servir de paradigma para o avanço das ações afirmativas nas universidades de todo país) foi fundamental a participação da então reitoria da UERJ que mudou sua percepção sobre a questão, passando a defender um sistema misto, que conjugasse as cotas raciais e sociais na universidade.

Na construção das políticas de cotas merece destaque a parceria que se consolidou entre o Movimento Negro, por meio da ONG Educafro e da reitoria da UERJ. A Educafro é uma ONG com centenas núcleos de pré-vestibulares comunitários, principalmente no Rio de Janeiro e em São Paulo, que promove o ingresso de jovens pobres e negros na educação superior. Por meio de convênios com universidades privadas, visando a concessão de bolsas teve forte atuação no processo de construção das cotas inspirando a criação de políticas públicas importantes como o Programa Diversidade na Universidade e o ProUni ${ }^{22}$.

A reitoria e o Governo do Estado instituíram grupos de trabalho que contavam com a participação de gestores da universidade, do governo e especialistas do movimento social e deste modo a política pode ser criada com certo consenso entrando em vigor no ano de $2003^{23}$. Conseguiu-se estabilizar a política e reduzir as ações judiciais contrarias às cotas. Deve-se ressaltar a importância do trabalho exercido pelos advogados do Movimento Negro, que aos poucos foram assentando a tese de que o sistema de cotas era constitucional, tendo inclusive que prestar assessoria voluntária e participar de diversos eventos jurídicos para capacitar magistrados, promotores e demais membros da Justiça. ${ }^{24}$

A ativa participação da reitoria, além de convencer os seus pares na UERJ, também possibilitou a construção de um acordo entre o Governo, a Assembleia Legislativa do Estado e os Movimentos Sociais. Por outro lado, a referida reitora se une

perceber nas próprias palavras da reitora das cotas numa de suas entrevistas: "Existia naquele momento uma enorme expectativa quanto ao que iria acontecer nos primeiros dias de aula. Suposições eram feitas na linha do conflito racial provocado pelas cotas. O que se viu para nossa alegria foi uma semana de calouros preparada com muito cuidado pelos veteranos para acolher os novos colegas. O que constatamos em unidades acadêmicas como a Faculdade de medicina, aonde fui pessoalmente assistir à aula inaugural, foi o brilho nos olhos daqueles jovens que chegavam aonde seus pais não puderam chegar. Estes alunos, os cotistas, aportaram às suas unidades acadêmicas e à seus colegas, saberes e experiências"

${ }^{24}$ No final desta fase, não havia mais candidatos questionando a constitucionalidade das cotas - até porque os advogados, promotores e defensores passaram a desaconselhar tais demandas jurídicas, por conta da interpretação favorável que o Judiciário passou a ter sobre a questão, adotando a tese dos advogados do Movimento Negro. Posteriormente, a pedido do Movimento Negro e da reitoria da UERJ, o presidente do Tribunal suspendeu todas as liminares deferidas contra as cotas. 
ao movimento nacional pró cotas e passa a viajar pelo Brasil influenciando dezenas de universidades a adotarem ações afirmativas. ${ }^{25}$

\section{O DESENVOLVIMENTO DAS AÇÕES AFIRMATIVAS NA EDUCAÇÃO SUPERIOR}

Sobre este aspecto é importante ressaltar que o Rio de Janeiro é uma verdadeira "caixa de ressonância nacional". Por conta do sistema de cotas no ensino superior ter sido instituído, primeiramente. nesse Estado foi algo significativo e paradigmático para impulsionar outras experiências no País. A partir do primeiro sistema houve uma profusão das ações afirmativas como formas de democratizar o acesso às universidades. Logo depois da implementação das cotas raciais na Universidade do Estado do Rio de Janeiro (UERJ) e na Universidade do Norte Fluminense em 2001 (UENF), o sistema de cotas foi adotado, no ano seguinte, pela Universidade Estadual da Bahia (Uneb) com percentual de $40 \%$ de suas vagas para estudantes negros e pela Universidade Estadual do Mato Grosso do Sul (UEMS) que aprovou cotas de 20\% para negros e 10\% para indígenas. Em 2003 o sistema de cotas foi adotado pela Universidade de Brasília (UNB), primeira instituição federal a criar uma política dessa natureza, com percentual de $20 \%$ para estudantes negros e pela Universidade de Alagoas (UFAL) que adotou cotas de $20 \%$ para estudantes negros.

No ano seguinte adotaram cotas para negros com percentuais diferenciados a Universidade Federal da Bahia (UFBA) e a Universidade Federal do Paraná (UFPR) e este avanço ajudou na aprovação da lei de $n^{\circ}$ 11.096/2005 que criou o Programa Universidade para todos relativo às instituições privadas, estabelecendo um sistema de cotas que também causa grande impacto na ampliação do ingresso de jovens negros na educação superior ${ }^{26}$.

que estavam à margem daquele ambiente e que faziam falta à formação. Falar que a diversidade agrega valor ao processo pedagógico não é uma abstração! Os dados de evasão e desempenho de nossos alunos estão aí para serem examinados e para derrubarem os mitos que se tenta construir" Vide Entrevista dada ao GELEDES em 2009. Disponível em www.geledes.org.br/exclusivo-ministra-nilcea-freire-reitora-da-uerjquando-as-cotas-foram-votadas-la/.

${ }^{26}$ O ProUni ofereceu um grande quantitativo de bolsas de estudo integrais e parciais, mediante isenção de impostos que as universidades recebem do Governo Federal. Ao regular o sistema de bolsas nas universidades privadas, determinou adoção do sistema de cotas para negros, indígenas e estudantes de escola pública por todas as instituições que aderirem a esse Programa que recebeu adesão progressiva de centenas de instituições privadas em todo o país. Como visto, ele produz grande impacto inclusivo, pois, a maioria das vagas do ensino superior pertencerem à rede privada. 
Por fim, este processo de democratização do acesso às universidades foi regulado pela lei 12.711/2012 que estabeleceu o sistema de cotas nas instituições federais de educação, Trata-se de um programa sistematizado que está promovendo o acesso de grupos minorizados às referidas instituições de ensino ${ }^{27}$.

As políticas de promoção da igualdade racial na educação superior, como dissemos, passaram por uma intensa judicialização. Mas se estabilizaram institucionalmente no Brasil a partir de 2012, por conta do julgamento da Arguição de Descumprimento de Preceito Fundamental (ADPF) 186, ajuizada na Corte pelo Partido Democratas (DEM) contra a política de cotas étnico-raciais da Universidade de Brasília (UnB). Ressalte-se que por unanimidade, os ministros julgaram improcedente a ADPF, considerando constitucional a política de cotas, na linha dos argumentos defendido pelos juristas negros, anos antes, nas ações da UERJ.

Assentou-se, a partir de então, que as políticas de ação afirmativa estabelecem um ambiente acadêmico plural e diversificado, e têm o objetivo de superar distorções sociais historicamente consolidadas. Além disso, os meios empregados e os fins perseguidos pelas universidades são marcados pela proporcionalidade, razoabilidade e as políticas são transitórias, com a revisão periódica de seus resultados. ${ }^{28}$

\section{OS IMPACTOS DEMOCRÁTICOS DAS COTAS NAS UNIVERSIDADES}

Vale ressaltar que as cotas reservaram, só nas universidades federais, milhares de vagas para negros e indígenas por ano, dado ao caráter inclusivo e redistributivo da

\footnotetext{
${ }^{27}$ Cabe analisar a lei 12.711/12 que dispõe sobre o ingresso nas universidades federais e nas instituições federais de ensino técnico de nível médio27. A referida lei obrigou as universidades federais a reservarem, em cada concurso seletivo, $50 \%$ de suas vagas, por curso e turno, para estudantes que tenham cursado integralmente o ensino médio em escolas públicas. Dentro deste percentual, estudantes pretos, pardos e indígenas deverão ser contemplados com uma proporção no mínimo igual ao número que estes grupos correspondam no Estado em que a universidade está situada, segundo o mais recente Censo Demográfico do Instituto Brasileiro de Geografia e Estatística (IBGE). A lei também se destina às instituições federais de ensino técnico de nível médio. Neste caso, também existem as cotas étnico-raciais na mesma proporção já citada. Ressalte-se apenas que os candidatos deverão ter cursado todo o ensino fundamental em escolas públicas $\left(\operatorname{artigo} 4^{\circ}\right.$ ). A lei determinou que o Ministério da Educação (MEC) e a Secretaria de Políticas de Promoção da Igualdade Racial (Seppir), ouvindo a Fundação Nacional do Índio (FUNAI), sejam os responsáveis pelo acompanhamento e avaliação do referido programa que deverá ocorrer no ano de 2022. A questão que envolve a revisão da lei cotas nas instituições federais fomenta muitas discussões, existem diversas iniciativas legislativas no Congresso Nacional, com destaque para o projeto de lei (PL 4.656/2020) do senador Paulo Paim (PT-RS) e o Projeto de Lei 1788/21, do deputado Bira do Pindaré (PSB-MA).
}

${ }^{28}$ Veja Ação de Descumprimento de Preceito Fundamental n. 186. Disponível em www.stfjus.gov.br Consultado em 15.01.2015. 
política. ${ }^{29}$ Trata-se de um importante programa que somado a outros completa uma série de políticas que foram adotadas para tornar mais democrático o direito à educação, Isto está trazendo um grande impacto social nas instituições federais e será determinante para diversificar as elites brasileiras nas próximas gerações.

No âmbito nacional, a política de inclusão nas universidades ainda carece de mecanismos que possibilitem seu monitoramento e avaliação, tendo em vista que um dos levantamentos potencialmente mais úteis para tal operação - o Censo da Educação Superior (CES) - apresenta elevados índices de não declaração racial. Contudo, há significativos avanços, comprovados por dados empíricos, Entre 2000 e 2010, houve um crescimento significativo no acesso à graduação. A presença de negros/as nos cursos de graduação, por exemplo, aumentou 290,7\% (ou 277,8\% para pardos e 384,0\% para pretos) no período considerado. na mesma linha, os dados afirmam que a razão entre brancos e negros foi profundamente modificada: "se em 2000 a relação era de quatro brancos para um negro na graduação, essa taxa diminuiu para dois brancos para cada negro em 2010"30.

Uma pesquisa divulgada pelo IBGE demonstrou que a maioria dos alunos da educação pública superior tinham se declarado preta ou parda. Não há estudos completos e oficiais sobre o impacto do ingresso e permanência de estudantes cotistas na educação superior, e ocorre certa discrepância dos dados do INEP e do IBGE e IPEA, contudo os estudos demonstram avanços significativos no que tangem o aumento de negros nas universidades. $^{31}$

De acordo com uma outra pesquisa do IBGE, o número de negros de 18 a 24 anos no ensino superior que em 2016 era de 50,5\% passou para 55,6\% em 2018. Já entre as

\footnotetext{
${ }^{29}$ Segundo dados Censo da Educação Superior, tabulados pelo LAESER em (2012) das 222.126 vagas geradas pelas universidades federais, pouco mais e oito mil tinham sido ocupadas por alunos negros e indígenas promovidos por ações afirmativas. Nos IFs e CEFETs, $41,2 \%$ do total de instituições aderiram à política de cotas de acesso (isto é, 14 das 36 instituições federais). Contudo, o número de ingressantes por meio desta ação afirmativa representou, em 2010 , apenas $4,8 \%$ do total de 25.555 novos estudantes e apenas 49 deles eram negros ou indígenas. Recentemente uma pesquisa do IBGE apontou que a maioria dos negros na educação superior. Os dados foram bastante contestados e pesquisadores aguardam novas divulgações para que se possa aferir melhor as recentes pesquisas do referido instituto.

${ }^{30}$ Veja em "Cor ou raça na Educação Superior. Disponível em <http://portal.inep.gov.br/informacao-dapublicacao/-/asset_publisher/6JYIsGMAMkW1/document/id/689605>CCnsultado em 19.10.2021.

${ }^{31}$ IBGE divulgou pesquisa com base na Pnad Contínua revelando que em 2018, o Brasil tinha mais de 1,14 milhão de estudantes autodeclarados pretos e pardos, enquanto os brancos ocupavam 1,05 milhão de vagas em instituições de ensino superior federais, estaduais e/ou municipais. Isso equivale, respectivamente, a $50,3 \%$ e 48,2\% dos mais de 2,19 milhões de brasileiros matriculados na rede pública.
} 
pessoas brancas, com a mesma idade, a proporção é de 78,8\%. A referida pesquisa mostra que a população negra, de um modo geral, goza de melhores índices educacionais, mas ainda se mantem bem atrás dos índices medidos entre as pessoas brancas. Na mesma faixa etária, o número de pretos e pardos com menos de 11 anos de estudo e que não estavam frequentando a escola caiu de 30,8\% em 2016 para $28,8 \%$ em 2018, enquanto o indicador para a população branca é de $17,4 \%{ }^{32}$

No caso do Rio de Janeiro, a política de cotas voltaria a ser alterada pela Lei 5.346/2008, e pela Lei nº 8121/2018 que está em vigor. Atualmente o Programa de Ação Afirmativa nas universidades públicas estaduais reservam $45 \%$ das vagas para todos que comprovem situação de hipossuficiência socioeconômica (rendimentos de até R\$ 1.017,00 per capita) distribuídos para os seguintes grupos:

I - $20 \%$ para alunos da rede pública de ensino;

II- 20\% para integrantes de minorias étnicas: negros (autodeclarados), quilombolas, indígenas (autodeclarados);

III - 5\% para pessoas com deficiência e para filhos de policiais civis e militares, bombeiros militares e inspetores de segurança e administração penitenciária, mortos ou incapacitados por razão de serviço, nos termos da legislação em vigor.

A experiência das universidades do Rio de Janeiro revelou a necessidade de construir um sistema de ações afirmativas que contemple um feixe de medidas que vão desde estimular estudantes pobres e negros a ingressarem na graduação, até a pósgraduação e inclusão no mercado de trabalho ${ }^{33}$.

Passemos à análise de alguns dados fornecidos pela UERJ ${ }^{34}$.

Quanto ao ingresso, a tabela a seguir demonstra a quantidade de alunos que entraram por meio do exame do Vestibular Estadual da UERJ desde a implementação do Sistema de cotas, de 2003 até 2020.

\footnotetext{
${ }^{32}$ Veja em "Pela primeira vez, negros são maioria no ensino superior público" Disponível em $<$ https://agenciabrasil.ebc.com.br/geral/noticia/2019-11/pela-primeira-vez-negros-sao-maioria-no-ensinosuperior-publico\#> . Consultado em 14.10.2021.

${ }^{33}$ Nas Universidades do Estado, o sistema de cotas também é adotado nos cursos de por graduação, por força da lei 6.914/14.

${ }^{34}$ Os dados fazem parte de em relatório estatístico sobre o Sistema de Cotas e são fornecidos pelo Departamento de Articulação, Iniciação Acadêmica e de Assistência e Inclusão Estudantil (Daiaie). Disponível em <http://www.daiaie.uerj.br/wpcontent/uploads/2021/06/RelatorioEstatisticoCompleto 150621.pdf $>$ Consultado em 01.11.2021.
} 
Figura 1: Dados sobre a inclusão de cotistas

\begin{tabular}{|c|c|c|c|c|c|c|c|c|c|}
\hline $\begin{array}{l}\text { Ano de } \\
\text { Ingresso }\end{array}$ & $\begin{array}{c}\text { Ampla } \\
\text { Concorrência }\end{array}$ & $\begin{array}{l}\text { Cota } \\
\text { Negro }\end{array}$ & $\begin{array}{l}\text { Cota } \\
\text { Rede } \\
\text { Pública }\end{array}$ & $\begin{array}{c}\text { Cota } \\
\text { Deficiente }\end{array}$ & $\begin{array}{l}\text { Cota } \\
\text { Filho }\end{array}$ & $\begin{array}{c}\text { Cota } \\
\text { Indigena }\end{array}$ & $\begin{array}{c}\text { Cota } \\
\text { Deficiente } \\
\text { ou } \\
\text { Indigena(") }\end{array}$ & $\begin{array}{l}\text { Total de } \\
\text { Ingressantes } \\
\text { por cota }\end{array}$ & $\begin{array}{l}\text { Total Geral } \\
\text { de } \\
\text { Ingressantes }\end{array}$ \\
\hline 2003 & 2.147 & 1.953 & 1.103 & 0 & 0 & 0 & 0 & 3.056 & 5.203 \\
\hline 2004 & 2.989 & 879 & 1.215 & 0 & 0 & 0 & 34 & 2.128 & 5.117 \\
\hline 2005 & 3.443 & 596 & 1.009 & 0 & 0 & 0 & 36 & 1.641 & 5.084 \\
\hline 2006 & 3.530 & 547 & 1.009 & 0 & 0 & 0 & 35 & 1.591 & 5.121 \\
\hline 2007 & 3.616 & 393 & 751 & 0 & 0 & 0 & 19 & 1.163 & 4.779 \\
\hline 2008 & 3.757 & 423 & 678 & 0 & 0 & 0 & 29 & 1.130 & 4.887 \\
\hline 2009 & 3.484 & 541 & 791 & 12 & 10 & 31 & 0 & 1.385 & 4.869 \\
\hline 2010 & 3.292 & 623 & 853 & 17 & 8 & 29 & 0 & 1.530 & 4.822 \\
\hline 2011 & 3.418 & 642 & 859 & 10 & 11 & 41 & 1 & 1.564 & 4.982 \\
\hline 2012 & 3.684 & 587 & 770 & 19 & 3 & 43 & 4 & 1.426 & 5.110 \\
\hline 2013 & 3.512 & 678 & 901 & 22 & 14 & 46 & 0 & 1.661 & 5.173 \\
\hline 2014 & 3.634 & 735 & 858 & 17 & 15 & 53 & 0 & 1.678 & 5.312 \\
\hline 2015 & 3.875 & 634 & 915 & 26 & 10 & 30 & 0 & 1.615 & 5.490 \\
\hline 2016 & 3.828 & 679 & 815 & 36 & 10 & 20 & 0 & 1.560 & 5.388 \\
\hline 2017 & 2.865 & 402 & 475 & 13 & 11 & 12 & 0 & 913 & 3.778 \\
\hline 2018 & 3.161 & 343 & 420 & 10 & 7 & 8 & 0 & 788 & 3.949 \\
\hline 2019 & 3.688 & 424 & 611 & 12 & 4 & 11 & 0 & 1.062 & 4.750 \\
\hline 2020 & 3.498 & 563 & 860 & 18 & 6 & 5 & 0 & 1.452 & 4.950 \\
\hline TOTAIS & 61.421 & 11.642 & 14.893 & 212 & 109 & 329 & 158 & 27.343 & 88.764 \\
\hline
\end{tabular}

Percebe-se pela tabela que em quase duas décadas, as políticas afirmativas propiciaram a entrada de quase trinta mil estudantes, destes, mais de onze mil são autodeclarados negros. Tal fato mostra o forte carater inclusivo da política.

Figura 2: Dados sobre a inclusão de cotistas em percentuais

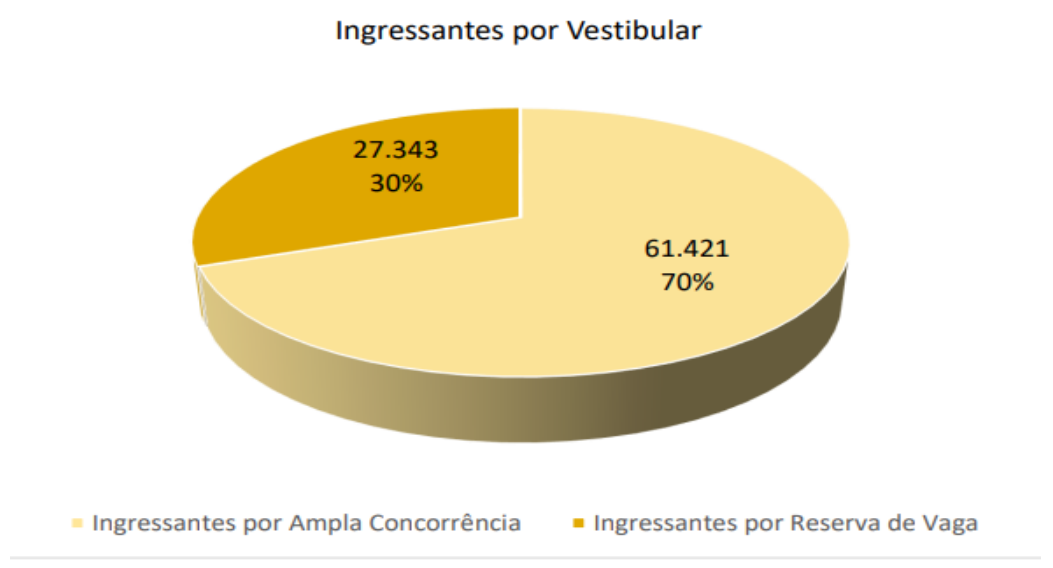

\section{Fonte: Daiaie/UERJ}

Este outro dado demonstra o real impacto das ações afirmativas no tempo. Em vinte anos, as cotas mudaram o perfil dos alunos. Hoje a universidade já conta com $30 \%$ do corpo discente composto por estudantes oriundos do sistema de cotas. Quem 
frenquentou a universidade antes das ações afirmativas e volta por lá hoje, se surpreende com o alunado que anda pelo campus, o corpo discente está em sintonia com a diversidade que encontramos na sociedade brasileira.

Figura 3: Dados sobre alunos cotistas concluintes
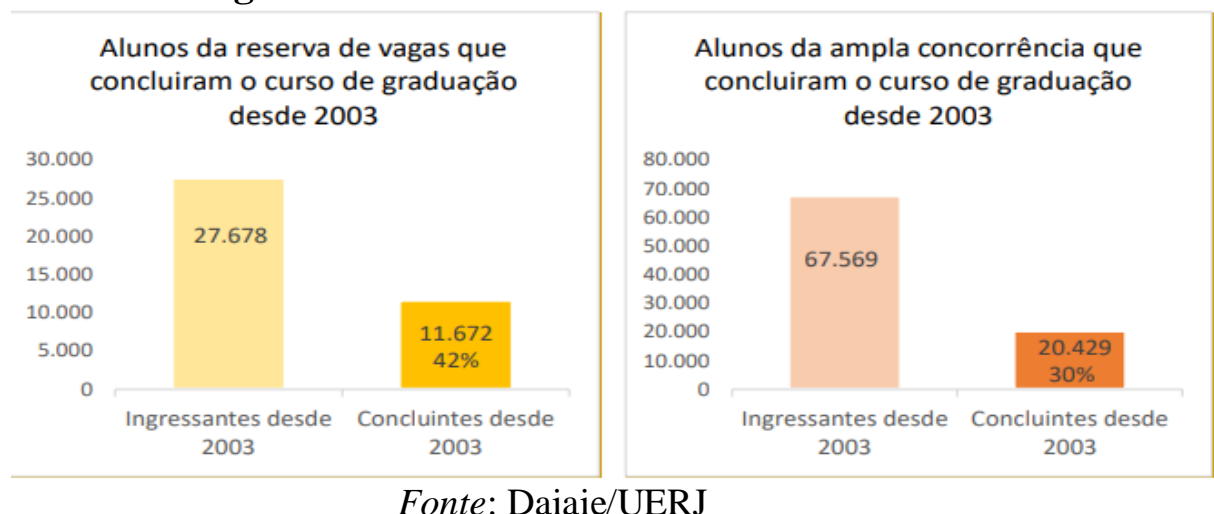

Fonte: Daiaie/UERJ

Figura 4: Dados sobre evasão Alunos Evadidos

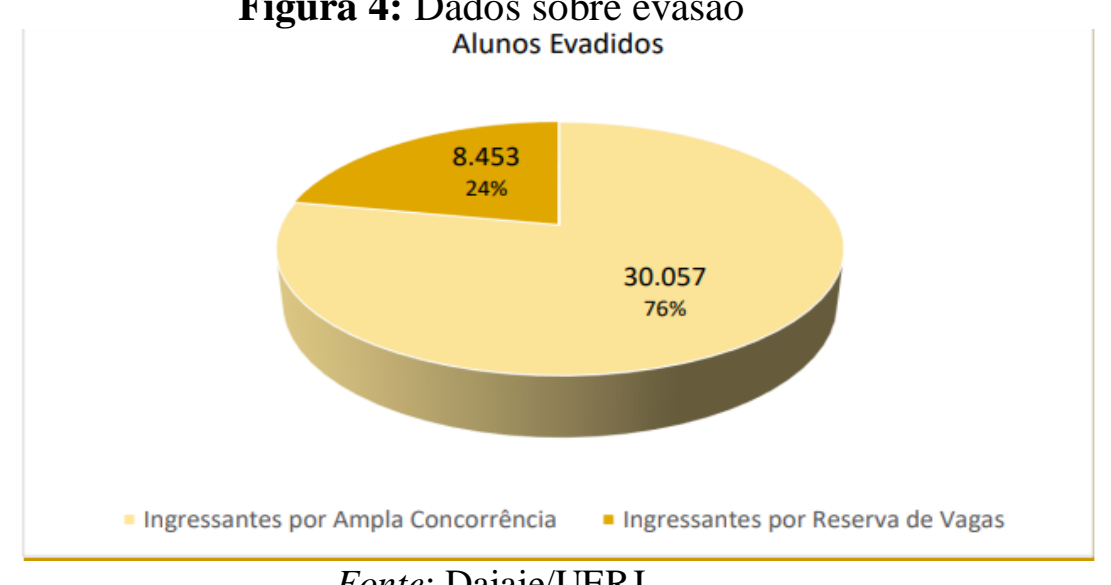

Fonte: Daiaie/UERJ

Quanto à permanência, os dados acima (sobre conclusão e evasão dos cursos) trazem uma análise comparativa entre estudantes cotistas e não cotistas (ampla concorrencia). É interessante observar que os alunos provientes das cotas, proporcionalmente, concluem mais os cursos, bem como tem menos evasão.

Tal fato em muito se explica porque o sistema de cotas adotado no Rio de Janeiro conta com uma política de permanêmcoa que, além de conferir uma bolsa (atualmente no valor de $\mathrm{R} \$ 500,00)$ para os alunos cotistas, também fornece uma série de atividades complementares, por meio de oficinas, seminários eventos culturais e parte do material didático, durante todo o curso universitário. 
Neste sentido, todos os que ingressaram na UERJ pela reserva de vagas têm acesso

à bolsa de estudos e às atividades instrumentais, como se demonstra na tabela abaixo.

Figura 5: Dados sobre a bolsa permanência e o quantitativo de alunos cotistas bolsistas

\begin{tabular}{|c|c|c|c|c|c|}
\hline & TOTAIS & QUANTITATIVO & TOTAIS & QUANTITATIVO & \\
\hline & POR MÊS BP & BOLSISTAS & POR MES & DE BOLSISTAS & VALORES DAS \\
\hline & GRADUAÇÃO UERJ & GRADUAÇÃO & BP CAP_UERJ & CAP & BOLSAS \\
\hline JAN/20 & $\mathrm{R} \$ 2.711 .050,00$ & 5.423 & $\mathrm{R} \$ 164.000,00$ & 328 & $\mathrm{R} \$ 500,00$ \\
\hline FEV $/ 20$ & $\mathrm{R} \$ 2.701 .750,00$ & 5.418 & $\mathrm{R} \$ 164.000,00$ & 328 & $\mathrm{R} \$ 500,00$ \\
\hline MAR/20 & $\mathrm{R} \$ 3.041 .250,00$ & 6.068 & $\mathrm{R} \$ 190.500,00$ & 381 & $\mathrm{R} \$ 500,00$ \\
\hline $\mathrm{ABR} / 20$ & $\mathrm{R} \$ 3.098 .550,00$ & 6.144 & $\mathrm{R} \$ 192.500,00$ & 383 & $\mathrm{R} \$ 500,00$ \\
\hline $\mathrm{MAl} / 20$ & $\mathrm{R} \$ 3.094 .300,00$ & 6.161 & $\mathrm{R} \$ 192.500,00$ & 384 & $\mathrm{R} \$ 500,00$ \\
\hline JUN/20 & $\mathrm{R} \$ 3.092 .000,00$ & 6.176 & $\mathrm{R} \$ 193.000,00$ & 385 & $\mathrm{R} \$ 500,00$ \\
\hline $\mathrm{JUL} / 20$ & $\mathrm{R} \$ 3.096 .000,00$ & 6.183 & $\mathrm{R} \$ 193.000,00$ & 386 & $\mathrm{R} \$ 500,00$ \\
\hline AGO/20 & $\mathrm{R} \$ 3.142 .000,00$ & 6.269 & $\mathrm{R} \$ 194.500,00$ & 388 & $\mathrm{R} \$ 500,00$ \\
\hline SET/20 & $\mathrm{R} \$ 3.172 .700,00$ & 6.332 & $\mathrm{R} \$ 194.500,00$ & 389 & $\mathrm{R} \$ 500,00$ \\
\hline OUT/20 & $\mathrm{R} \$ 3.140 .500,00$ & 6.272 & $\mathrm{R} \$ 194.000,00$ & 388 & $\mathrm{R} \$ 500,00$ \\
\hline NOV/20 & $\mathrm{R} \$ 3.200 .500,00$ & 6.334 & $\mathrm{R} \$ 194.000,00$ & 388 & $\mathrm{R} \$ 500,00$ \\
\hline DEZ/20 & $\mathrm{R} \$ 3.175 .600,00$ & 6.338 & $\mathrm{R} \$ 194.000,00$ & 388 & $\mathrm{R} \$ 500,00$ \\
\hline TOTAL & $\mathrm{R} \$ 36.666 .200,00$ & & $\mathrm{R} \$ 2.260 .500,00$ & & \\
\hline
\end{tabular}

Fonte: Daiaie/UERJ

Sobre o desempenho acadêmico de ingresso (dados referentes às notas do vestibular), verifica-se que há diferenças entre cotistas e não-cotistas no processo seletivo de acesso à graduação. Geralmente o rendimento dos cotistas é inferior ao dos não cotistas no processo seletivo, o que faz todo sentido e justifica de modo objetivo a necessidade da política.

Já em relação ao índice de aproveitamento em disciplinas (rendimento acadêmico durante o curso), as pesquisas ao longo do tempo, demonstraram que os cotistas possuem desempenho maior do que o dos não-cotistas, em diversos cursos. Sobre isso se pode cogitar que os cotistas conseguem um bom rendimento por conta da forte política de assistência estudantil, somada a determinação que estes alunos têm por conta de terem alcançado o ensino superior, muitos inclusive, sendo os primeiros em suas familias. ${ }^{35}$

\footnotetext{
${ }^{35}$ Sobre o rendimento acadêmico, os dados da UERJ não estão atualizados. Mas uma pesquisa revelada pela universidade em 2010, mostrava que "os egressos da rede pública apresentaram rendimento médio de 6,56 e os negros, de 6,41. Entre os demais estudantes a média foi de 6,37. Outro levantamento mostrou que a aprovação dos beneficiários das ações afirmativas foi de $83,15 \%$, contra $81,2 \%$ dos demais alunos da instituição. Disponível em <https://www.camara.leg.br/noticias/143489-cotistas-tem-desempenho-similara-media-geral/> Consultado em 20.10.21.
}

Já outra pesquisa sobre desempenho feita em 2017, por uma comissão instaurada pela Procuradoria Geral do Estado do Rio de Janeiro (PGE-RJ) avaliou o sistema de cotas e concluiu que não há diferenças significativas no rendimento de cotistas e não cotistas. "A análise dos dados apresentados permite desmistificar a ideia de que a cota provocaria um decréscimo de qualidade do ensino em instituições públicas de ensino superior do Estado do Rio de Janeiro", diz o relatório elaborado pelo órgão. Veja em <https://www.camara.leg.br/noticias/143489-cotistas-tem-desempenho-similar-a-media-geral/>

Consultado em 10.11.2021. 
Vale lembrar que uma pesquisa realizada pelo Grupo de Estudos Multidisciplinar da Ação Afirmativa (GEEMA/UERJ) sobre desempenho dos estudantes, apontou que os dados da Universidade Federal do Piauí, Universidade de Brasília, Universidade Federal da Bahia, Universidade Estadual de Londrina, Universidade Tecnológica Federal do Paraná e Universidade Federal do Rio Grande do Norte, reafirmam o bom desempenho dos estudantes cotistas. Tal fato comprova que carece de validade empírica, pois não se comprovou o argumento sobre desempenho de cotistas ser inferior e produzir impactos negativos na qualidade da educação superior $^{36}$.

O processo de inclusão promovido pelas políticas afirmativas seguiu por outras instituições. Em 2011 uma lei reservou vagas para negros e indígenas nos concursos públicos estaduais ${ }^{37}$. Já em 2014 uma outra norma adotou as cotas, no mesmo sentido, para os concursos públicos do Município do Rio de Janeiro ${ }^{38}$.

Ressalte que a lei Estadual 6.914/14 instituiu o sistema de cotas nas instituições públicas de ensino superior nos cursos de pós-graduação, incluindo mestrado, doutorado, cursos de especialização, aperfeiçoamento, dentre outros. O objetivo da norma é assegurar gratuitamente aos graduados o "aprimoramento, qualificação e a especialização profissional", desde que carentes e preenchidos os demais requisitos legais. A lei determinou que, no máximo, $20 \%$ do total de vagas da pós-graduação deverão ser reservadas com os seguintes critérios: (a) 12\% para estudantes graduados negros e indígenas; (b) $12 \%$ para graduados da rede pública e privada de ensino superior e (c) $6 \%$ para pessoas com deficiência, filhos de policiais civis e militares, bombeiros militares e

\footnotetext{
36 Disponível em 〈http://gemaa.iesp.uerj.br/wp-content/uploads/2019/12/TD-Desempenho-final.pdf> Consultado em 20.10.21.
}

${ }^{37}$ Lei ${ }^{\circ} 6067$, de 25 de outubro de 2011, que foi substituída pela lei no 6740 de 02 de abril de 2014.

"Art. $1^{\circ}$ ficam reservadas aos negros e índios $20 \%$ (vinte por cento) das vagas oferecidas nos concursos públicos para provimento de cargos efetivos e empregos públicos integrantes dos quadros permanentes de pessoal do poder legislativo, judiciário, ministério público, Tribunal de Contas do Estado do Rio de Janeiro e Executivo do Estado do Rio de Janeiro e das entidades de sua Administração Indireta. Art. $3^{\circ}$ Está Lei entrará em vigor na data de sua publicação." Disponível em <http://alerjln1.alerj.rj.gov.br/CONTLEI.NSF/c8aa0900025feef6032564ec0060dfff/147a61100ab37c848 3257caf006095c9? OpenDocument > Consultado em 10.10.2021.

${ }^{38}$ Lei 5695/2014. “Art. $1^{\circ}$ Fica reservado aos negros e índios o percentual correspondente a vinte por cento das vagas oferecidas nos concursos públicos para provimento dos cargos e empregos públicos dos quadros permanentes de pessoal da administração direta e indireta do Município do Rio de Janeiro. ” Disponível em

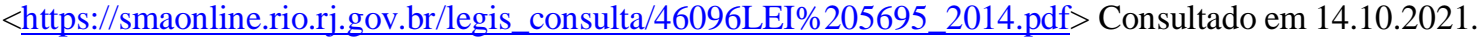


inspetores de segurança e administração penitenciária, mortos ou incapacitados em razão do serviço. ${ }^{39}$

Por derradeiro, devemos ainda relatar que a partir deste ano os processos seletivos para os cursos de graduação e pós-graduação terão uma comissão para analisar a autodeclaração étnico-racial dos candidatos. A proposta foi aprovada pelo Conselho Superior da universidade, visando dar mais segurança na efetividade da política de cotas raciais. A referida Comissão será formada por 60 membros da comunidade acadêmica (20 docentes, 20 servidores técnico-administrativos e 20 estudantes), obedecendo a critérios de gênero e raça quanto à diversidade. ${ }^{40}$

\section{CONCLUSÃO}

Podemos ressaltar, criticamente que, a promoção da igualdade racial em sociedades é uma questão complexa que vem se impondo como imperativo republicano e deve ressoar nas instituições de poder. Neste sentido, para que possam se afirmar como legítimas e democráticas, as instituições devem ter em seus quadros uma composição igualitária dos mais variados sujeitos, culturas e subjetividades, que compõem e contribuíram para a formação da sociedade na qual a instituição está inserida. Desta forma, as políticas de ação afirmativa deram certo e se estabilizaram de modo inexorável na educação superior. Elas promovem um acesso mais democrático às universidades, muito embora esse nível educacional continue ainda difícil de ser alcançado.

A experiência das universidades do Rio de Janeiro nos convida a refletir sobre muitos dos seus desdobramentos positivos. Há problemas? Sim. Fraudes, falta de recursos, um monitoramento mais preciso dos impactos das políticas por todo país, além de uma articulação entre as instituições e as empresas para se otimizar a promoção de talentos ávidos por mais oportunidades. O sistema de cotas precisa e pode ser sempre aprimorado.

As cotas para as pessoas negras, em especial, marcam o fim da democracia racial na educação, democratizam um dos espaços mais importantes para a reprodução do poder

\footnotetext{
${ }^{39}$ Disponível em $<$ https://www.migalhas.com.br/depeso/210871/a-reserva-de-vagas-para-pos-graduacaonas-universidades-estaduais-do-rj. Consultado em 15.10.2021>

40 Disponível em 〈https://www.uerj.br/noticia/uerj-aprova-criacao-de-comissao-para-validarautodeclaracao-etnico-racial-em-concursos/> Consultado em 17.10.2021.
} 
e do saber, estimulam nossa juventude a vencer na vida por meio do acesso ao conhecimento crítico, contribuem para diversificar nossas elites e ajudam a transformar a vidas de milhares de pessoas.

Esse processo, ainda em curso, não está mais relacionado somente à graduação. As cotas foram adotadas no mestrado, doutorado e também nos concursos públicos estaduais e municipais visando integrar-se o mercado de trabalho.

Com as cotas, a democratização que o antirracismo promove criou instituições mais justas, uma verdadeira transformação social se consolidou nos últimos anos.

O Brasil precisa cada vez mais, reconhecer para libertar. Consignar o consenso de que estudantes negros e pobres a partir das cotas estão mudando a universidade para melhor, e por elas transformando o país. As ações afirmativas são uma realidade, um fato social potente e democrático, que se desenvolvem em diversas áreas, fomentando a cidadania e tornando possível o que antes delas era impensável.

\section{REFERÊNCIAS BIBLIOGRÁFICAS}

AMADEO, Javier. Identidade, reconhecimento e redistribuição: uma análise crítica do pensamento de Charles Taylor, Axel Honneth e Nancy Fraser. Disponível em <https://periodicos.ufsc.br/index.php/politica/article/view/2175-7984.2017v16n35p242>

Acessado em 20.20.2020.

ALMEIDA, Silvo Luiz. O que é racismo estrutural? Minas Gerais: Letramento, 2018.

AVRITZER Leonardo; Lilian C. B. Gomes Política de reconhecimento, raça e democracia no Brasil. Disponível em: <www.scielo.br/scielo.php?script=sci arttext\&pid=S001152582013000100003> Consultado em 20.20.2020.

BEZERRA, Teresa Olinda Caminha \& Gurgel. Claudio Roberto Marques. A política pública de cotas na UERJ: desempenho e inclusão Disponível em <http://www.anpad.org.br/admin/pdf/2012_EnAPG407.pdf> Consultado em 17.10.2021.

BORGES, Lázaro Alves. Cotas raciais e universidades públicas: direito fundamental à educação como forma de equiparação. Disponível em: <http://www.brjd.com.br/index.php/ BRJD /article/ view/2534/2551> Consultado em 11.09.2020.

BRASIL, SUPREMO TRIBUNAL FEDERAL. Racismo, conceito, evolução e tratamento jurídico. STF. Atualizada até o DJE de 2 de agosto de 2018 e o Informativo STF 908. Brasília 2018. Disponível em: <http://www.stf.jus.br/arquivo/ cms/publicacaoPublicacao Tematica/anexo/ igualdade_etnico_racial.pdf > Consultado em 10.08.2020.

. Ministério da Educação. Conselho Nacional de Educação/Câmara de Educação

Superior Resolução $\mathrm{n}^{\circ}$ 5, de 17 de dezembro de 2018. Disponível em <http://www.in.gov.br/materia/-/asset publisher/Kujrw0TZC2Mb/content/id/55640393/do12018-12-18-resolucao-n-5-de-17-de-dezembro-de-2018-55640113> Consultado em 10.09.2021. 
COSTA NETO, Antonio Gomes da. Ações afirmativas na Administração Pública Federal: a política multicultural da lei de cotas no serviço público. Disponível em $<$ https://educacaopublica.cecierj.edu.br/artigos/16/18/aes-afirmativas-na-administrao-pblicafederal-a-poltica-multicultural-da-lei-de-cotas-no-servio-pblico > Consultado em 09.09.2021.

d'ADESKY, Jacques. Recursos para o Reconhecimento, igualdade e respeito. Rio de Janeiro. Cassará, 2018.

DOS SANTOS, Adilson Pereira, Bruno Camilloto, Hermelinda Gomes Dias. A heteroidentificação na ufop: o controle social impulsionando o aperfeiçoamento da política pública. Revista da ABPN • v. 11, n. 29 • jun - ago 2019, p.15-40 Disponível em <https://www.repositorio.ufop.br/bitstream/123456789/12455/1/ARTIGO_Heteroidentifica\%C3 \%A7\%C3\%A3oUFOPControle.pdf > Consultado em 20.10.2021.

FERES Jr. Cotas no STF: Os argumentos como eles são. Disponível em <http://gemaa.iesp.uerj.br/JFJ/artigos/> Consultado em 16.01.2020.

. Jonas (orgs.). Ação afirmativa e universidade: experiências nacionais comparadas. Brasília: Editora UnB, 2006.

FERREIRA. Renato (Org.) Ações Afirmativas: a questão das cotas, análises jurídicas de um dos assuntos mais controvertidos da atualidade. Niterói, RJ. Editora Impetus, 2011.

.10 anos de promoção da igualdade racial: balanços e desafios. Disponível em $<$ http://www.flacso.org.br/dez anos governos pos neoliberais/archivos/10 ANOS GOVERN OS.pdf> Consultado em 12.01.2015.

Et al. O Manifesto em Defesa das Cotas. Disponível em: $<$ http://www1.folha.uol.com.br/fsp/cotidian/ff1405200808.htm> Consultado em 12.01.2021.

A luta internacional contra a discriminação racial. Noticia Preta. Disponível em: $<$ https://noticiapreta.com.br/a-luta-internacional-contra-a-discriminacao-racial/> Consultado em 20.08.2021.

FIGUEIREDO, Eduardo Henrique Lopes. Uma análise da reserva de vagas em concursos públicos federais, 2016. Disponível em: $<$ http://www.mpsp.mp.br/portal/page/portal/documentacao

_e_divulgacao/doc_biblioteca/bibli_servicos_produtos/bibli_boletim/bibli_bol_2006/fieo10.pdf $>$ Consultado em 09.09.2020.

FREITAS, Jefferson B. de, Poema Eurístenes Portela João Feres Júnior Águida Bessa Vivian Nascimento Políticas de Ação Afirmativa nas Universidades Federais e Estaduais (2013-2018). Disponível em : <http://gemaa.iesp.uerj.br/wp-content/uploads/2020/07/Levantamento-das-AAs2018b.pdf> Consultado em 07/10.2021

GOMES, Joaquim Barbosa. Ação Afirmativa e Princípio Constitucional da Igualdade, Rio de Janeiro: Renovar. 2001.

GUIMARÃES, Reinaldo da Silva. Afrocidadanização - Ações Afirmativas e Trajetórias de Vida no Rio de Janeiro - PUC Rio, 2017.

LÁZARO André... [et al.] (Orgs.). Nilcea Freire, mulher em movimento: Primeiro movimento: UERJ [recurso eletrônico] / - Rio de Janeiro: LPP/ UERJ, 2020.

MACHADO, Elielma Ayres Coleção estudos afirmativos, 2: ação afirmativa, reserva de vagas e cotas na Universidade do Estado do Rio de Janeiro (2002-2012) / Elielma Ayres Machado; organização André Lázaro e Laura Tavares. - Rio de Janeiro: FLACSO, GEA; UERJ, LPP, 2013. 
MARINHO. Adriana Costa \& Carvalho, Márcia Haydee Porto de. Ações afirmativas e o princípio da igualdade: cotas raciais, um instrumento social para a promoção da igualdade de oportunidades. In Revista Ceuma Perspectivas, vol. 31, 2018.

MELLO E SOUZA Alberto de. Desempenho dos candidatos no vestibular e o sistema de cotas na UERJ Disponível em: <https://www.scielo.br/j/ensaio/a/qkmfrKYzBPV5bYZjvfgxDdj/abstract/?lang=pt> Consultado em 17.10.2021.

MENDES JUNIOR, Alvaro Alberto Ferreira Uma análise da progressão dos alunos cotistas sob a primeira ação afirmativa brasileira no ensino superior: o caso da Universidade do Estado do Rio de Janeiro. Disponível em: 〈https://www.scielo.br/j/ensaio/a/dLNVHQSf3zTQZT5QjNdmSsm/abstract/?lang=pt〉

Consultado em 17.10.2021

PAIXÃO, Marcelo, O Justo Combate: relações raciais e desenvolvimento em questão. Disponível em: 〈http://periodicos.ufes.br/simbiotica/article/viewFile/11721/8418> Consultado em 10.09.2020.

SANTOS, Boaventura de Sousa. Para uma sociologia das ausências e uma sociologia das emergências. Disponível em: $\langle\underline{\text { http://www.boaventuradesousasantos.pt/media/pdfs/Sociologia_das_ausencias_RCCS63.PDF> }}$ Consultado em 20.08.2021.

Boaventura de Souza. Justiça Social e Justiça Histórica. Ação Afirmativa nos EUA. In: Renato Ferreira (Org.). Ações Afirmativas a Questão das Cotas, Rio de Janeiro: Impetus, 2011. Políticas de Ação Afirmativa nas Universidades Federais e Estaduais (2013-2018) Jefferson B. de Freitas Poema Eurístenes Portela João Feres Júnior Águida Bessa Vivian Nascimento.

SILVA, Jorge da. Direitos Civis e relações raciais no Brasil. Rio de Janeiro Editora: LUAM, 1994.

SILVA Jr. Hédio. Direito de Igualdade Racial. Editora: Juarez de Oliveira São Paulo: 2002.

SOUSA, Alice Ribeiro Concurso Público e Ações Afirmativas -Lumen Juris, 2018.

THEODORO Mário (org.), Luciana Jaccoud, Rafael Osório, Sergei Soares. As políticas públicas e a desigualdade racial no Brasil: 120 anos após a abolição / - Brasília: Ipea, 2008.

Recebido em: 01/10/2021

Aprovado em: 20/11/2021 